\title{
Comparison of diastolic function in children with transfusion dependent beta thalassemia major by tissue and conventional doppler imaging indices and its correlation with serum ferritin levels
}

\author{
Chetan Kumar Nanjegowdaㄹ, Sowmini Padmanabh Kamath ${ }^{2}$, Padmanabh Kamath ${ }^{3}$, \\ Tejas Dushyantbhai Shah ${ }^{4}$, Vaman Kulkarni ${ }^{5}$, Harsha Prasada Lashkari ${ }^{2}$, Bantwal Shantharam \\ Baliga $^{2}$ \\ ${ }^{1}$ Department of Pediatrics, University of Miami/Jackson Memorial Hospital, Miami, Florida, USA; Departments of \\ ${ }^{2}$ Pediatrics, ${ }^{3}$ Cardiology and ${ }^{5}$ Community Medicine, Kasturba Medical College, Mangalore, Manipal Academy of Higher \\ Education, Manipal, Karnataka, ${ }^{4}$ Department of Cardiology, Smt.B.K Shah Medical Institute and Research Centre,Sumandeep \\ Vidyapeeth University,Vadodara, India. E-mail: kamathsowmini@yahoo.com \\ Received: 18th April 2018, Revised: 21st June 2018, Accepted: 26th June 2018
}

SUMMARY: Nanjegowda CK, Kamath SP, Kamath P, Shah TD, Kulkarni V, Lashkari HP, Baliga BS. Comparison of diastolic function in children with transfusion dependent beta thalassemia major by tissue and conventional doppler imaging indices and its correlation with serum ferritin levels. Turk J Pediatr 2019; 61: 250-259.

Regular blood transfusions for children with beta thalassemia major ( $\beta$ TM) results in iron overload cardiomyopathy/cardiac failure. Mortality in these children is most often because of heart failure. We compared Tissue Doppler Imaging (TDI) and conventional pulse wave Doppler (PWD) indices in evaluating diastolic function in chronically transfused $\beta$-TM children and correlated the Doppler indices with mean serum ferritin levels.

This was a prospective cross-sectional study conducted at tertiary teaching hospital. $\beta$-TM children aged 3 to 18 years were enrolled as per inclusion criteria. PWD parameters at the mitral inflow (E, A, E/A and DT) and TDI parameters at the medial mitral annulus ( $\mathrm{E}^{\prime}$ and $\left.\mathrm{E} / \mathrm{E}^{\prime}\right)$ were used for estimation of diastolic dysfunction.

Of the 66 children with thalassemia, the mean age was $10.2 \pm 3.77 \mathrm{yrs}$ and $60.6 \%$ were boys. The $\mathrm{E} / \mathrm{E}^{\prime}$ ratio estimated diastolic dysfunction $(34 / 66,51.5 \%)$ greater than four times that assessed by $\mathrm{E} / \mathrm{A}$ ratio indices $(8 / 66,12.1 \%)$ in the subjects. Association of serum ferritin levels with $\mathrm{E} / \mathrm{E}^{\prime}$ ratio by chi square test was significant statistically $(P=0.027)$, however was not significant with E/A ratio. By Mann Whitney test, the median serum ferritin levels ( $\mathrm{ng} / \mathrm{ml}$ ) were higher [4034.50, (IQR-2084-5340.25) in those with diastolic dysfunction (abnormal E/E'), when compared to those with normal E/E'[2037.50(1510.753572.25)], with their difference being significant $(p=0.011)$, however serum ferritin levels were not significant with $E / A$ ratio and DT. E/E' parameter had a sensitivity and specificity of $76.5 \%$ and $53.1 \%$ respectively at a mean serum ferritin cutoff level of $2076 \mathrm{ng} / \mathrm{mL}$ by ROC analysis.

In conclusion, TDI is a more reliable modality for diagnosing early diastolic dysfunction when compared to PWD. Threshold level of serum ferritin greater than $2076 \mathrm{ng} / \mathrm{mL}$ is associated with increased incidence of diastolic dysfunction.

Key words: beta thalassemia, child, diastole, ferritin, iron overload.

Thalassemia major $(\beta-\mathrm{TM})$ is an inherited hemoglobin disorder caused by impaired synthesis (either partial or complete suppression) of beta globulin chains, resulting in chronic hemolytic anemia. ${ }^{1}$ Worldwide each year, approximately 100,000 children are born with thalassemia major. It is estimated that there are about $65,000-67,000 \beta$-TM patients 
in India with 9,000-10,000 cases being added every year. ${ }^{2}$ Regular blood transfusion as a treatment modality, builds up iron overload in the body leading to organ damage. ${ }^{3}$

Cardiac involvement secondary to iron overload remains the major cause of mortality and morbidity. ${ }^{4}$ Myocardial iron deposition could be minimized, with early and aggressive chelation therapy. ${ }^{5}$ Serum ferritin levels are used to assess the degree of iron overload and treatment effectiveness. ${ }^{6,7}$

In our clinical practice, echocardiography plays a vital role in assessing myocardial iron overload. Diastolic dysfunction precedes the onset of systolic failure. ${ }^{8}$ Tissue and conventional doppler echocardiography reflects myocardial and red blood cell motion abnormalities respectively caused by myocardial iron deposition. Tissue Doppler Imaging (TDI) can be a reliable investigation in developing countries where MRI is not easily available and expensive. ${ }^{7}$ Studies 9,10 have documented that TDI picks up diastolic dysfunction at early stages.

Previous studies, ${ }^{6,10}$ have also demonstrated pulse wave Doppler (PWD) associations between serum ferritin levels and diastolic dysfunction. Thus, our goal was to study the utility of TDI and PWD modalities in detecting early diastolic dysfunction, before development of overt cardiomyopathy and also to assess the association between diastolic dysfunction and serum ferritin level. The latter could guide us to initiate early and aggressive chelation therapy in these children.

\section{Material and Methods}

This hospital based cross sectional study was conducted from November 2013-August 2015 in tertiary care hospitals attached to Kasturba Medical College, Mangalore, Manipal Academy of Higher Education, Manipal, an urban area in the coastal area of Karnataka State, India. Children with $\beta$-TM aged 2 to 18 years, on regular blood transfusions for more than one year with last serum ferritin levels greater than $500 \mathrm{ng} / \mathrm{ml}$ were enrolled in the study. Sample size was calculated based on $E^{\prime}$ value (combined standard deviation of $E^{\prime}=3.3$, d-difference between means of $\left.E^{\prime}-4.9\right),{ }^{11} 90 \%$ power, $95 \%$ confidence interval, and $10 \%$ non-response rate as 58 subjects. Approval from the institutional Ethics Committee (IEC) (dated 16/10/2013, reference no: IEC KMC MLR 10-13/186) was obtained. Necessary permissions were taken from the hospital authorities. Hospitals were visited for data collection. The study subjects were selected using sequential (nonrandom) sampling technique. $\beta$-TM subjects with febrile illness, congestive cardiac failure and congenital/structural heart disease were excluded from the study. For the selected study participants, their parents/guardians were approached and the objectives of the study was explained in a language they understood and a participant information letter was provided to them. A written informed consent/assent was obtained from each one of the parent/ guardian/subjects. Data collection was done using a semi-structured pretested proforma, which included details about the demographic factors and medical history.

Following this, under aseptic precautions, non-fasting venous blood was drawn from the study population prior to the start of blood transfusion into procoagulant vacutainer. Samples were stored at -4 to -8 degree Fahrenheit and ferritin was estimated by using Ferritin ELISA KIT (Calbiotech, USA.). The test sample result obtained was compiled, the last three ferritin levels were derived from the case records. For better reflection of cardiac iron status, mean was calculated using these four serum ferritin levels (so as to represent the two yearly mean value of ferritin) and used for statistical analysis. Based on their ferritin values, they were categorized into three groups : $<2500 \mathrm{ng} / \mathrm{ml}, 2500-5000 \mathrm{ng} / \mathrm{ml}$, and $>5000 \mathrm{ng} / \mathrm{ml}$.

Echocardiography was performed on a GEVIVID E9, Version-112 machine (GE Vingmed, Horten, Norway) using M5S-D active matrix single crystal phased array transducer with frequency range of $1.5-4.5 \mathrm{MHz}$ with a 120 -degree field of view and tissue velocity imaging capabilities. The patients underwent TDI and PWD during the same visit in the cardiology department. The diastolic function assessment using PWD was measured at mitral inflow and TDI at medial mitral annular level. (Iron deposition occurs initially in the interventricular septum). ${ }^{7,12}$ The TDI and PWD were performed by two cardiologists to avoid interpersonal variation. Serum ferritin values were blinded to the cardiologists to prevent bias. Echocardiography 
data were obtained at the end of expiration with the subject at rest, lying in the lateral supine position with simultaneous ECG monitoring over three cardiac cycles. The echo study was performed closest in time to the serum ferritin measurement estimation. The images were recorded in the standard parasternal long axis, apical four-chamber, and two-chamber views.

Operational definitions: ${ }^{13}$ (values based on age)

Tissue Doppler Echocardiography: Left ventricular myocardial tissue Doppler imaging was performed with sample volume placed at the septal margin of mitral annulus and the variables $E^{\prime}(m . s-1)$ - Peak early diastolic velocity at mitral annulus expressed in m.s-1 and $\mathrm{E} / \mathrm{E}^{\prime}$-the ratio of transmitral flow velocity to annular velocity were included to evaluate diastolic function.

Conventional Pulse Wave Echocardiography: PWD imaging was done at the mitral valve inflow during three consecutive cardiac cycles. The variables such as mitral E velocity $(\mathrm{m} / \mathrm{sec})$ : early mitral inflow, mitral A velocity (m/ $\mathrm{sec}$ ): late mitral inflow, their ratio mitral E/A and deceleration time (DT) interval (msec) - (from the early peak velocity to the zero intercept) were determined for assessing diastolic function.

The primary outcome measure was to identify and compare diastolic dysfunction with two different echocardiographic modalities (TDI and PWD) as per their indices. Secondary outcome measure was to correlate these Doppler indices and find out if there was any association with serum ferritin levels.

\section{Statistical analysis}

Patient characteristics were expressed in proportions. TDI, PWD parameters and serum ferritin levels were expressed as mean $\pm 2 S D$. Associations were derived using Chi Square and Mann Whitney test. A p value of $<0.05$ was considered significant. Linear Correlation between diastolic indices (E/A, DT, E/E') and mean serum ferritin levels were measured by Pearson correlation coefficient. A ROC (receiver operating characteristic) curve was performed to obtain cut off for ferritin levels to diagnose diastolic dysfunction.Analysis was done using Statistical Package for Social Sciences (SPSS Version 11.5, Chicago IL).
Table I. Baseline Characteristics of Children with Beta Thalassemia.

\begin{tabular}{|c|c|}
\hline Clinical profile & Frequency (\%) \\
\hline \multicolumn{2}{|l|}{ Gender } \\
\hline Male & $40(60.6)$ \\
\hline Female & $26(39.4)$ \\
\hline \multicolumn{2}{|l|}{ Age } \\
\hline $3-5 \mathrm{yr}$ & $10(15.2)$ \\
\hline $6-9 \mathrm{yr}$ & $20(30.3)$ \\
\hline $10-13 \mathrm{yr}$ & $21(31.8)$ \\
\hline $14-18 \mathrm{yr}$ & $15(22.7)$ \\
\hline \multicolumn{2}{|l|}{ Frequency of transfusion } \\
\hline 3 week and below & $20(30.3)$ \\
\hline 4 week and above & $46(69.7)$ \\
\hline \multicolumn{2}{|l|}{ Age at diagnosis } \\
\hline Below 1 yr & $39(59.1)$ \\
\hline $1 \mathrm{yr}$ and above & $27(40.9)$ \\
\hline \multicolumn{2}{|l|}{ Weight for age } \\
\hline Underweight for age & $41(62.1)$ \\
\hline Normal & $25(37.9)$ \\
\hline \multicolumn{2}{|l|}{ Height for age } \\
\hline Stunted & $41(62.1)$ \\
\hline Normal & $25(37.9)$ \\
\hline \multicolumn{2}{|l|}{ Duration of transfusion } \\
\hline $2-5 \mathrm{yr}$ & $23(34.8)$ \\
\hline $5-10 \mathrm{yr}$ & $19(28.8)$ \\
\hline$>10 \mathrm{yr}$ & $24(36.4)$ \\
\hline \multicolumn{2}{|c|}{ Transfusion index (ml/kg/year) } \\
\hline$<100$ & $5(7.6)$ \\
\hline $100-150$ & $13(19.7)$ \\
\hline $150-200$ & $15(22.7)$ \\
\hline$>200$ & $33(50)$ \\
\hline \multicolumn{2}{|l|}{ Liver size in $\mathrm{cm}$} \\
\hline Normal & $3(4.5)$ \\
\hline$<3$ & $17(25.8)$ \\
\hline $3-5$ & $28(42.2)$ \\
\hline $6-10$ & $17(25.8)$ \\
\hline$>10$ & $3(4.5)$ \\
\hline \multicolumn{2}{|l|}{ Spleen size in $\mathrm{cm}$} \\
\hline Normal & $18(27.3)$ \\
\hline$<3$ & $10(15.2)$ \\
\hline $3-5$ & $14(21.2)$ \\
\hline $6-10$ & $23(34.8)$ \\
\hline$>10$ & $1(1.5)$ \\
\hline \multicolumn{2}{|l|}{ Chelation medications } \\
\hline Defarisirox & $55(83.33)$ \\
\hline Deferiprone & $5(7.58)$ \\
\hline None & $6(9.09)$ \\
\hline
\end{tabular}




\section{Results}

A total of 66 children with $\beta$-TM were included with their baseline demographic characteristics and clinical variables, depicted as in Table I. Mean age of the study subjects was $10.2 \pm 3.77$ years. More than $50 \%$ were in the second decade. $Z$ scores for anthropometric indices were calculated. Most of the children followed normal distribution for body weight and prevalence of stunting was $3 / 66(4.5 \%)$. Z scores for BSA was abnormal in one three year old child (2.04), who had stunting with weight being normal. TDI $\mathrm{E} / \mathrm{E}^{\prime}$ ratio was abnormal in 34 $(51.5 \%)$ cases indicating diastolic dysfunction. PWD E/A ratio suggesting diastolic dysfunction was abnormal in $8(12.1 \%)$ cases. Thus, TDI estimated diastolic dysfunction greater than four times that by PWD. Diastolic dysfunction by deceleration time (DT) was present in $53.1 \%$ [above normal levels: $11 / 66(16.7 \%)$, and below normal levels: 24/66(36.4\%)]. E/E'ratio was abnormal in 10 (29.4\%), 13(38.2\%) and $11(32.4 \%)$ of subjects with serum ferritin of $>5000 \mathrm{ng} / \mathrm{ml}, 2500-5000 \mathrm{ng} / \mathrm{ml}$ and $<2500$ $\mathrm{ng} / \mathrm{ml}$ respectively (Table II) . This association was statistically significant ( $p$ value -0.027 ) However, by chi-square the association of serum ferritin levels with E/A ratio and DT was not significant.

By Mann Whitney test, the median serum ferritin levels $(\mathrm{ng} / \mathrm{ml})$ were higher [4034.50, (IQR-2084-5340.25) in those with diastolic dysfunction (abnormal E/E'), when compared to those with normal levels E/E'[2037.50(1510.753572.25)], with their difference being significant $(p=0.011)$, however serum ferritin levels were not significant with $\mathrm{E} / \mathrm{A}$ ratio and DT.

We observed positive correlation between
$\mathrm{E} / \mathrm{E}^{\prime}$ indices and mean serum ferritin levels with correlation co efficiency of +0.36 , which suggests an intermediate positive correlation status between the variables (Fig. 1). However, the diastolic parameters DT and E/A had negative correlation status with serum ferritin levels $(r=-0.150$, and $r=-0.032$ respectively). A ROC analysis (Fig. 2) was obtained to determine the cutoff of mean serum ferritin level that correlated with diastolic dysfunction. It was found that at $2076 \mathrm{ng} / \mathrm{ml}$ level, the E/E' ratio had a sensitivity of $76.5 \%$ and specificity of $53.1 \%$.

\section{Discussion}

Cardiac complications account for $50 \%-70 \%$ of mortality in patients with $\beta$-TM. ${ }^{14}$ Cardiac dysfunction is multifactorial in origin; cardiac iron overload is predominating. It is characterized by early diastolic dysfunction in the disease course, ${ }^{8}$ hence cardiac evaluation is essential on a regular basis at follow-ups. International guidelines recommend annual cardiac monitoring after 8 years of age. Here we used PWD and TDI modalities to assess diastolic functions.

TDI estimated diastolic dysfunction greater than four times when compared to that estimated by PWD in our study, thus indicating earlier detection by TDI within the subjects. Similarly a study by Parale et al. ${ }^{9}$ on $\beta$-TM children, showed significant increase in $\mathrm{E} / \mathrm{E}$ ann $\left(\mathrm{E} / \mathrm{E}^{\prime}\right)$ ratio $(\mathrm{P}<0.0001)$ by $\mathrm{TDI}$, but had no significant difference in E/A ratio by PWD between cases and controls. The peak myocardial early diastolic velocity ratio $\mathrm{Em}\left(\mathrm{E}^{\prime}\right)$, was lower among cases when compared with controls, the difference being significant $(<0.001)$ as per

Table II. Association of E/E' with Mean Serum Ferritin Levels.

\begin{tabular}{|c|c|c|c|c|}
\hline \multirow{2}{*}{ Ferritin level mean(ng/ml) } & \multicolumn{2}{|c|}{$\mathrm{E} / \mathrm{E}^{\prime} \mathrm{LV}$} & \multirow[b]{2}{*}{ Total } & \multirow{2}{*}{$P$ value } \\
\hline & Normal & Abnormal & & \\
\hline$<2500$ & $\begin{array}{c}19 \\
(59.4 \%)\end{array}$ & $\begin{array}{c}11 \\
(32.4 \%)\end{array}$ & $\begin{array}{c}30 \\
(45.5 \%)\end{array}$ & \\
\hline $2500-5000$ & $\begin{array}{c}8 \\
(25 \%)\end{array}$ & $\begin{array}{c}13 \\
(38.2 \%)\end{array}$ & $\begin{array}{c}21 \\
(31.8 \%)\end{array}$ & $P=0.027$ \\
\hline$>5000$ & $\begin{array}{c}5 \\
(15.6 \%)\end{array}$ & $\begin{array}{c}10 \\
(29.4 \%)\end{array}$ & $\begin{array}{c}15 \\
(22.7 \%)\end{array}$ & \\
\hline Total & $\begin{array}{c}32 \\
(100 \%)\end{array}$ & $\begin{array}{c}34 \\
(100 \%)\end{array}$ & $\begin{array}{c}66 \\
(100 \%)\end{array}$ & \\
\hline
\end{tabular}

E/E'- transmitral flow velocity to annular velocity ratio, $\mathrm{p}$ value ${ }^{*}$ Chi square test 


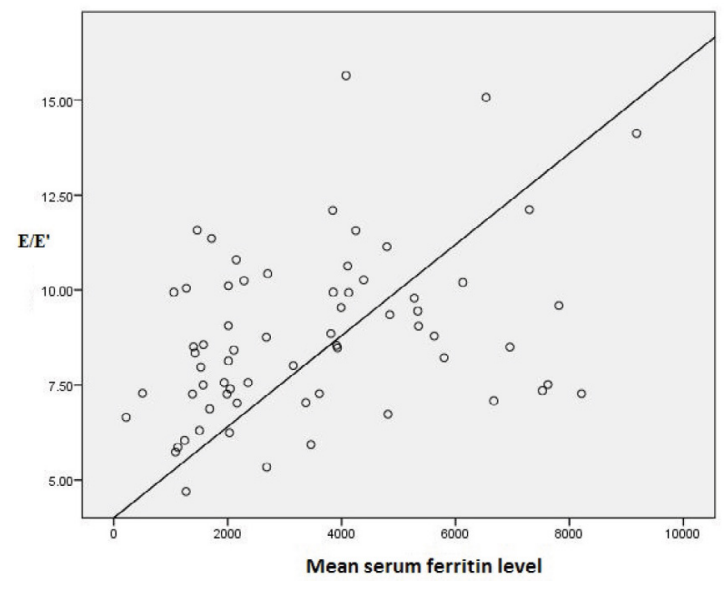

Fig. 1. The positive correlation between $\mathrm{E} / \mathrm{E}^{\prime}$ indices and mean serum ferritin levels with correlation co efficiency of +0.36 , which suggests an intermediate positive correlation status between the variables

Aypar et al. ${ }^{15} \mathrm{~A}$ study by Ragab et al ${ }^{10}$, showed the mean $\mathrm{E}^{\prime}$ as well as its values at anterior, inferior and lateral walls of the mitral annulus were significantly lower in TM patients when compared to the controls, however abnormal $\mathrm{E} / \mathrm{E}^{\prime}$ was not documented in any of the $\beta$-TM patients. This was discordant from our study. Gujja et al. ${ }^{12}$ had hypothesized that iron deposition in the heart was patchy, predominantly affecting the septal portion of the ventricles initially, with rest of the ventricular mass getting affected at later stages. The peak myocardial early diastolic velocity in a study by Saravi et al., 16 measured at mid septal wall was statistically significant $(p<0.05)$, however the same measured from basal lateral LV and mid lateral LV wall were not significant, corroborating Gujja et al. ${ }^{12}$ hypothesis. E/E' parameter assessment in the present study was done at the medial wall. Similarly, Yildirim et al. ${ }^{17}$ documented $\mathrm{E} / \mathrm{E}^{\prime}$ ratio (measured from the midseptal, lateral and basal walls) in $\beta$-TM children to be significantly higher than those of the controls. $(p=0.012, p<0.001, p=0.001$, respectively).

In day to day clinical practice, a widely accepted biochemical assay of serum ferritin levels aids clinicians in assessing severity of iron overload status and treatment effectiveness. ${ }^{6,7}$ Single ferritin levels will not be conclusive on the cardiac iron status. Yearly trends of ferritin levels reflect iron body load. Cardiac involvement and mortality could be predicted

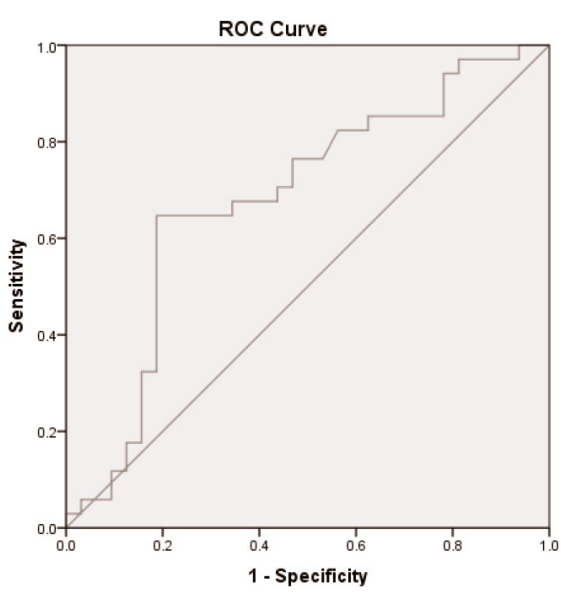

Diagonal segments are produced by ties.

Fig. 2. Receiver operating characteristic (ROC) curve of serum ferritin levels in predicting diastolic dysfunction. Area under curve $=0.68, \mathrm{SE}=0.068, \mathrm{P}$ value $=0.011,95 \%$ confidence interval $(\mathrm{CI})=0.55-0.82$. At cut off point 2076 $\mathrm{ng} / \mathrm{ml}$, sensitivity $=76.5 \%$, specificity $=53.1 \%$.

as a result of long term elevations in serum ferritin levels. ${ }^{18}$ In our study we had taken average of four values from last two years (so as to represent the two yearly mean value of ferritin), to have a better reflection of cardiac iron status.

In this study, there was significant association between $\mathrm{E} / \mathrm{E}^{\prime}$ ratio and serum ferritin levels. In our study, $\mathrm{E} / \mathrm{E}^{\prime}$ ratio of TDI was abnormal in $32.4 \%$ subjects with serum ferritin level of $<2500 \mathrm{ng} / \mathrm{ml}$, this is in is in contrast to Silvilairat et al, ${ }^{6}$ wherein his subjects with levels $<2500 \mathrm{ng} / \mathrm{ml}$ had preserved diastolic function. Olivieri et al, ${ }^{19}$ and Bosi et al, ${ }^{20}$ suggested the cardiovascular prognosis was excellent in children if serum ferritin was maintained below $2500 \mathrm{ng} / \mathrm{ml}$.

We found an intermediate positive correlation status of +0.36 between $E / E^{\prime}$ and serum ferritin levels. Studies by Silvilairat et al. ${ }^{6}$ and Garadah et $\mathrm{al}^{21}$ ( $\mathrm{r}=0.56, \mathrm{r}=+0.74$ respectively) found a significant positive correlation status between these variables. However Rohimi et al,22 found a negative correlation $(r=-0.174)$ status between $\mathrm{E} / \mathrm{E}^{\prime}$ and serum ferritin levels. Additionally, Yildirim et al. ${ }^{17}$ found no association between diastolic dysfunction and serum ferritin levels. A negative correlation status between diastolic parameters (E/A and DT) by PWD documented in our study, was concordant with study by Azhena et al. $^{23}$ and was not similar to the 
study by Silvilairat et al. ${ }^{6}$

A ROC curve analysis performed to obtain a cut off for serum ferritin level to diagnose LV diastolic dysfunction was determined at 2076 $\mathrm{ng} / \mathrm{ml}$ in our study. At that cut off value $\mathrm{E} /$ $E^{\prime}$ had sensitivity of $76.5 \%$, and specificity of $53.1 \%$. In a study by Ragab et al, 10 on Egyptian children, diastolic dysfunction predicted by E/ $E^{\prime}$ ratio $\geq 8$, was based on serum ferritin cutoff level of $4790.5 \mathrm{ng} / \mathrm{ml}$ by ROC curve. Significant higher serum ferritin levels were noted in patients with $E / E^{\prime} \geq 8$ when compared with those with ratio of $<8$. Their cut off values are more than twice that of our study. Low prevalence of myocardial iron deposition by cardiovascular magnetic resonance (MRI T2*) in the Egyptian $\beta$-TM patients in spite of very high serum ferritin and high liver iron was documented by El Beshlawy et al. ${ }^{24}$ and this fact could possibly explain diastolic dysfunction to occur at a higher serum ferritin cut off values in study by Ragab et al. ${ }^{10}$ Also as suggested by Ragab et al. ${ }^{10}$ ethnic differences and genetic susceptibilities to cardiac iron overload in different populations warrants large scale studies.

The gold standard test to estimate cardiac iron load status is by cardiac MRI (CMR).

Vogel et al. ${ }^{7}$ assessed 52 asymptomatic patients with $\beta$-TM with a mean age of 29.2 (14.2-43.1) years by TDI and CMR. As per Vogel et al., abnormal myocardial iron loading (T2* $<20 \mathrm{~ms})$ by CMR was present in $73 \%$ of patients. TDI detected wall motion abnormalities in $88 \%$ of patients with abnormal $\mathrm{T} 2 *$ in his study. Vogel et al, ${ }^{7}$ in his study documented that TDE in comparison with the gold standard CMR, detects abnormal iron loading with a sensitivity of $88 \%$ and specificity of $65 \%$. Similarly Aypar et al. ${ }^{15}$ documented abnormal iron loading by CMR (T2* $\leq 20 \mathrm{~ms}$ ) in $25 / 33$ cases, with the peak myocardial early diastolic velocity ratio $($ Em $)$ by TDI to be lower $(p<0.05)$. Hence it had been concluded that TDI could be a reliable investigation in developing countries, where MRI is not easily available and is expensive.

The present study has a few limitations. The normal reference values for Doppler parameters were derived from American society of Echocardiography charts. These values may have ethnic and demographic variability. CMR is the gold standard to demonstrate iron deposition in the heart; this was not evaluated in our study. Regional wall motion abnormalities and strain rate imaging were not studied by tissue Doppler imaging. Also the parameter TE-e' (time interval between peak of $R$ wave in QRS complex and onset of mitral $\mathrm{E}$ velocity is subtracted from the time interval between QRS complex and onset of $\mathrm{e}^{\prime}$ velocity) and the difference of pulmonary vein atrial reversal flow and mitral valve $A$ wave duration (PVAR-MVA) for assessing diastolic dysfunction were not assessed due to its feasibility issues. In this study, the duration and dosage of intravenous and subcutaneous chelation therapy, type of chelation therapy in relation to diastolic dysfunction was not studied. We also feel that the sample size of the study was not adequate to detect important differences in the parameters as intended earlier. We suggest large scale studies in the future would probably demonstrate a cut off value with a higher sensitivity and specificity.

In conclusion, asymptomatic children with $\beta$-TM demonstrated abnormal diastolic indices more with TDI when compared with PWD, indicating TDI to be more reliable than PWD in estimating diastolic dysfunction at earlier stages. The TDI estimation of diastolic dysfunction by E/ $\mathrm{E}^{\prime}$ ratio from medial mitral annulus correlated significantly with serum ferritin levels. Serum ferritin greater than $2076 \mathrm{ng} / \mathrm{ml}$, was associated with increased incidence of diastolic dysfunction in the study subjects. In our clinical scenario serum ferritin is one of the markers to assess iron over load; hence TDI parameter $E / E^{\prime}$ is a reliable parameter of myocardial iron overload and can be used to monitor therapy in children with $\beta$-TM.

\section{Acknowledgements}

We thank the children, parents/guardians who consented to participate in the study

\section{REFERENCES}

1. DeBaun MR, Frei-Jones MJ, Vichinsky EP. Hemoglobinopathies. In: Kliegman RM, Stanton BF ST Geme III JW, Schor NF (eds). Nelson Textbook of Pediatrics $\left(20^{\text {th }}\right.$ ed) Vol. 2. Philadelphia: Elsevier, 2016: 2336-2345.

2. Thacker $\mathrm{N}$. Prevention of thalassemia in India. Indian Pediatr 2007; 44: 647-648.

3. Tanner MA, Galanello R, Dessi C, et al . Combined chelation therapy in thalassemia major for the treatment 
of severe myocardial siderosis with left ventricular dysfunction. J Cardiovasc Magn Reson 2008; 10: 12.

4. Telfer P, Coen PG, Christou S, et al. Survival of medically treated thalassemia patients in Cyprus. Trends and risk factors over the period 1980-2004. Haematologica 2006; 91: 1187-1192.

5. Kremastinos DT, Farmakis D. Iron overload cardiomyopathy in clinical practice. Circulation 2011; 124: 2253-2263.

6. Silvilairat S, Sittiwangkul R, Pongprot Y, Charoenkwan P, Phornphutkul C. Tissue Doppler echocardiography reliably reflects severity of iron overload in pediatric patients with $\beta$ thalassemia. Eur J Echocardiogr 2008; 9: 368-372.

7. Vogel M, Anderson LJ, Holden S, Deanfield JE, Pennell DJ, Walker JM. Tissue Doppler echocardiography in patients with thalassaemia detects early myocardial dysfunction related to myocardial iron overload. Eur Heart J 2003; 24: 113-119.

8. Kremastinos DT, Hamodraka E, Parissis J, Tsiapras D, Dima K, Maisel A. Predictive value of B-type natriuretic peptides in detecting latent left ventricular diastolic dysfunction in beta-thalassemia major. Am Heart J 2010; 159: 68-74.

9. Parale GP, Pawar SS, Tapare VS. Assessment of LV diastolic function in patients with beta-thalassemia major with special reference to E/Eann ratio. J Pediatr Hematol Oncol 2009; 31: 69-73.

10. Ragab SM, Fathy WM, El-Aziz WF, Helal RT. The diagnostic value of pulsed wave tissue doppler imaging in asymptomatic beta- thalassemia major children and young adults; relation to chemical biomarkers of left ventricular function and iron overload. Mediterr J Hematol Infect Dis 2015; 7: e2015051.

11. Abdelmoktader AM, Azer HY. Usefulness of pulsed wave tissue doppler imaging in assessment of left ventricular functions in children with beta-thalassemia major. Indian J Pediatr 2013; 80: 721-725.

12. Gujja P, Rosing DR, Tripodi DJ, Shizukuda Y. Iron overload cardiomyopathy: better understanding of an increasing disorder. J Am Coll Cardiol 2010; 56: 1001-1012.

13. Eidem BW, McMahon CJ, Cohen RR, et al. Impact of cardiac growth on doppler tissue imaging velocities: a study in healthy children. J Am Soc Echocardiogr 2004; 17: 212-221.

14. Kirk P, Roughton M, Porter JB, et al. Cardiac T2* magnetic resonance for prediction of cardiac complications in thalassemia Major. Circulation 2009; 120: 1961-1968.

15. Aypar E, Alehan D, Hazirolan T, Gumruk F. The efficacy of tissue Doppler imaging in predicting myocardial iron load in patients with beta-thalassemia major: correlation with $\mathrm{T} 2 *$ cardiovascular magnetic resonance. Int J Cardiovasc Imaging 2010; 26: 413-421.

16. Saravi M, Tamadoni A, Jalalian R, Mahmoodi-Nesheli H, Hojati M, Ramezani S. Evaluation of tissue doppler echocardiography and $\mathrm{T} 2^{*}$ magnetic resonance imaging in iron load of patients with thalassemia major. Caspian J Intern Med 2013; 4: 692-697.

17. Turedi-Yildirim A, Oymak Y, Yaman Y, et al. Examination of echocardiographic parameters for the early diagnosis of cardiac dysfunction in beta thalassemia major patients. Med Sci Discov 2014; 1: 35-43.

18. Pennell DJ, Udelson JE, Arai AE, et al; American Heart Association Committee on Heart Failure and Transplantation of the Council on Clinical Cardiology and Council on Cardiovascular Radiology and Imaging. Cardiovascular function and treatment in $\beta$-thalassemia major: A consensus statement from the American Heart Association. Circulation 2013; 128: 281-308.

19. Olivieri NF, Brittenham GM. Management of the thalassemias. Cold Spring Harb Perspect Med 2013; 3. pii: a011767.

20. Bosi G, Crepaz R, Gamberini MR, et al. Left ventricular remodelling, and systolic and diastolic function in young adults with beta thalassaemia major: a Doppler echocardiographic assessment and correlation with haematological data. Heart 2003; 89: 762-766.

21. Garadah TS, Mahdi N, Kassab S, Shoroqi IA, AbuTaleb A, Jamsheer A. The pro-BNP serum level and echocardiographic tissue doppler abnormalities in patients with beta thalassemia major. Clin Med Insights Cardiol 2010; 4: 135-141.

22. Rohimi S, Advani N, Sastroasmoro S, et al. Tissue doppler imaging in thalassemia major patients: correlation between systolic and diastolic function with serum ferritin level. Paediatr Indones 2012; 52 187-193.

23. Ashena Z, Ghafurian S,Ehsani MA. The relation between left ventricular diastolic indices and serum ferritin in thalassemia major. Pediatr Hematol Oncol 2007; 24: 3-14.

24. El Beshlawy A, El Tagui M, Hamdy M, et al. Low prevalence of cardiac siderosis in heavily iron loaded Egyptian thalassemia major patients. Ann Hematol 2014; 93: 375-379. 